\title{
Long-term remission of left posterior fascicular ventricular tachycardia due to mechanical trauma
}

\author{
PETR PARIZEK, M.D., PH.D., JIRI POPELKA, LUDEK HAMAN, M.D., PH.D.
}

1st Department of Internal Medicine, University Hospital, Charles University Prague, Faculty of Medicine, Hradec Kralove, Czech Republic. Conflict of interest: None declared.

Recibido el 7 de junio de 2010 . Aceptado el 2 de agosto de 2010.

Address correspondence to: Petr Parizek, MD, PhD, 1st Department of Internal Medicine, University Hospital, Sokolska 581, 50005 Hradec Kralove, Czech Republic. Tel+fax: + 420495833017 . E-mail address: parizek@ fnhk.cz

\section{ABSTRACT}

We present a case of a 28-year-old woman with paroxysmal left posterior fascicular ventricular tachycardia (LPFVT). Ventricular tachycardia was not inducible after completing of left ventricle $3 D$ reconstruction. Even though catheter ablation was not performed, no LPFVT recurrence has been documented during 60 months' follow-up. We surmise that we caused mechanical trauma during the mapping of the posterior fascicle that damaged arrhythmogenic structures and subsequently led to long-term remission of the left posterior fascicular ventricular tachycardia.

(Rev Med Chile 2010; 138: 1008-1011).

Key words: Cardiac electrophysiology; Catheter ablation; Tachycardia, ventricular.

\section{Remisión espontánea de una taquicardia fascicular posterior izquierda paroxística causada por trauma mecánico. Informe de un caso}

Presentamos una mujer de 28 años, portadora de una taquicardia fascicular posterior izquierda paroxística que no pudo ser inducida después de completar una reconstrucción en tres dimensiones del ventrículo izquierdo. A pesar no haber efectuado una ablación por electrofulguración, la taquicardia no ha reaparecido después de 60 meses de seguimiento. Suponemos que causamos un trauma mecánico durante el mapeo del fascículo posterior, que dañó las estructuras arritmogénicas. Esto llevó a una remisión a largo plazo de la arritmia.
I diopathic ventricular tachycardia (VT) is composed of multiple discrete subtypes that are best differentiated by their mechanism, VT morphology, site of origin, and the successful ablation site. These VTs are not associated with structural heart disease. The most common idiopathic VT originates in the outflow tract of the right ventricle, and its mechanism is triggered automaticity. Less common idiopathic left VTs are classified into three subgroups according to the mechanism: adenosine-sensitive type (triggered activity), propranolol-sensitive type (automaticity), and verapamil-sensitive type (reentry), which is the most frequent form of idiopathic left VT. Left posterior fascicular VT (LPFVT) with characteristic diagnostic right bundle branch block and left-axis configuration is the dominant subtype of verapamil-sensitive VT. Catheter ablation has been proposed as therapy of choice for all types of idiopathic VTs today ${ }^{1,2}$.

\section{Case report}

The patient was a 28-year-old woman with a six-year history of palpitations. Initially, she responded well to beta-blocker therapy. Subsequent 
difficulties required progressively higher doses, but they were not tolerated (hypotension). Palpitation attacks occurred during rest as well as during physical activity a few times a month and sometimes took several hours to resolve. Monomorphic ventricular tachycardia (VT) with right bundle branch block morphology and left axis deviation, with a rate 140 - 160 beats/min, was repeatedly documented (Figure 1, panel A). Echocardiography and magnetic resonance imaging of the heart failed to reveal any abnormality.

In March 2005 the patient was admitted with incessant VT (rate 146 beats/min), which was successfully terminated by administration of ve- rapamil $5 \mathrm{mg}$ intravenously. Because the patient refused to undergo catheter ablation, we continued with conservative treatment: verapamil $120 \mathrm{mg}$ daily (higher doses were not well tolerated). After additional episodes of VT in May 2005, the patient gave informed consent for catheter ablation, verapamil was withdrawn, and the patient underwent electrophysiological evaluation. During sinus rhythm, we mapped the left ventricular septum and left posterior fascicle (Figure 1, panel B). VT was not inducible after the map completion, hence the procedure was terminated, and catheter ablation was not performed. The next-day ECG was normal; no humoral response occurred. During

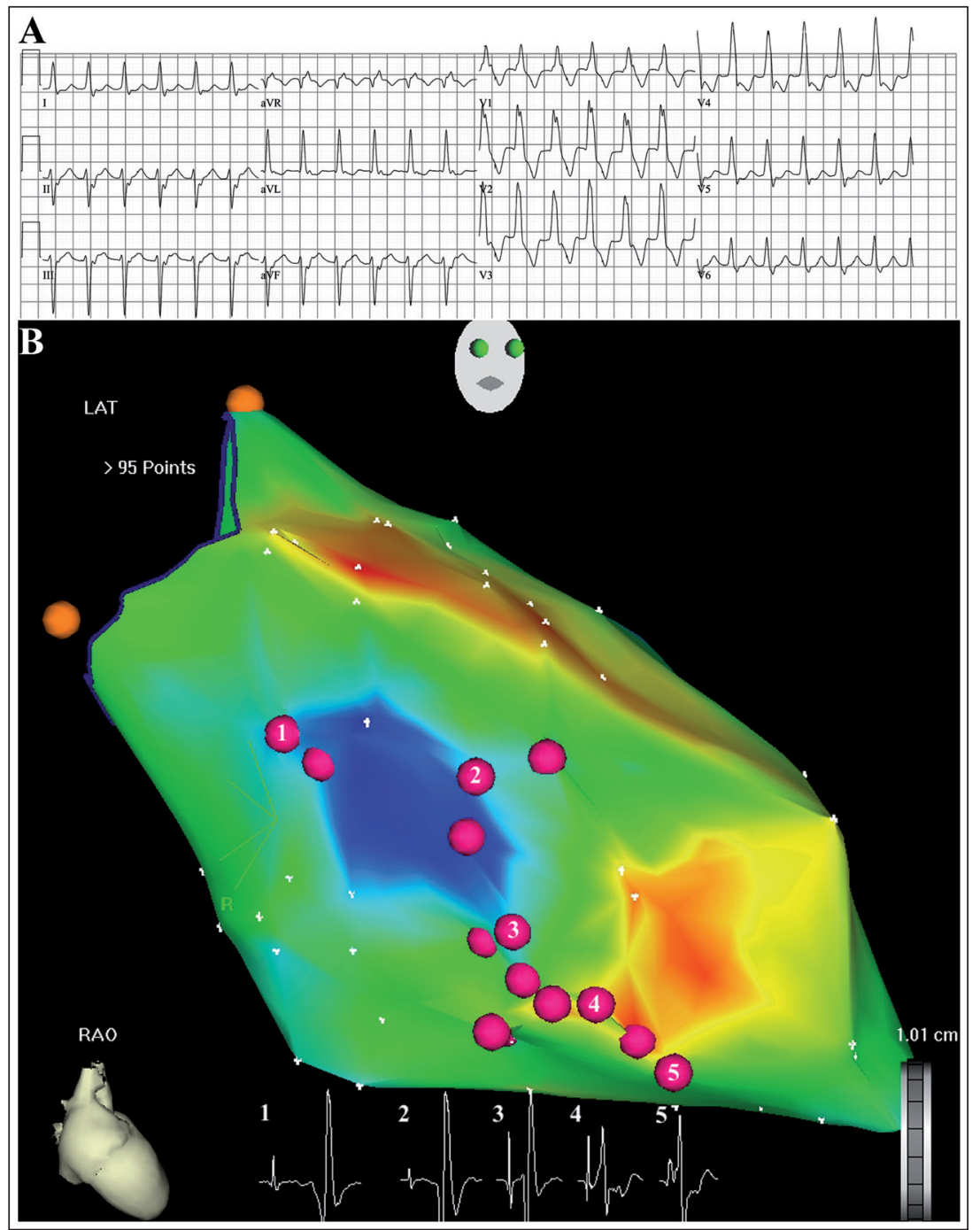

Figure 1. Panel A: Surface 12-lead ECG: monomorphic ventricular tachycardia-left posterior fascicular VT with right bundle-branch block and left axis deviation morphology. Panel B: 3D CARTO map of left ventricle [RAO 30 view], course of left bundle branch and posterior fascicle is marked with violet points with corresponding intracardiac signals [1-5, spiky potentials preceding ventricular potentials] at the bottom of the Figure. 
60 months of follow-up, palpitations and VT have not recurred; the patient has not received antiarrhythmic drugs during this period.

\section{Discussion}

The anatomic basis of LPFVT has provoked considerable interest. Potential substrate of the VT could be small fibromuscular bands, trabeculae carneae, and small papillary muscles. The Purkinje networks in these small anatomic structures are important when considering the reentry circuit of LPFVT. ${ }^{\text {. }}$

Catheter ablation has been reported to have high success rates in terminating LPFVT. Radiofrequency ablation was applied during VT; terminating the VT or abolishing the inducibility of the tachycardia was used as an endpoint for successful ablation. A presystolic or diastolic potential preceding the QRS complex, presumed to originate from the Purkinje fibers, can be recorded during sinus rhythm and also in VT. This potential has been used as a guide to catheter ablation. Ouyang et $\mathrm{al}^{3}$ demonstrated successful ablation with a single radiofrequency pulse application at the site with mechanical termination of LPFVT. Successful ablation sites differed. While Nakagawa's ${ }^{4}$ ablation sites were at the apical-inferior septum, Tsuchiya's ${ }^{5}$ ablation sites were at basal septal regions close to the main trunk of the left bundle branch. Results of these studies suggest the presence of a macroreentry circuit involving the normal Purkinje system and abnormal Purkinje tissue with decremental properties and verapamil-sensitivity. ${ }^{1} \mathrm{Ma}$ et $\mathrm{al}^{6}$ showed that the left posterior fascicular block in the surface electrocardiogram can be used as an effective endpoint of ablation. It is important especially in those patients whose VT cannot be induced or when the inducible condition is unstable.

Conduction block over anatomical structures sometimes occurs during manipulation of catheters in the cardiac chambers. This conduction block is ascribed to mechanical trauma and is referred to as "catheter-induced trauma". Catheter-induced trauma has been reported in the atrioventricular node ${ }^{7,8}$, the His bundle ${ }^{9}$, the right bundle branch ${ }^{10}$, the atrium ${ }^{11}$, and the accessory pathways ${ }^{11,12}$. Catheter-induced mechanical trauma incidence was reported in $2-14 \%$ of patients receiving radiofrequency ablation for supraven- tricular tachycardia ${ }^{8,11,12}$. However, the recurrence rate in these patients was significantly higher because the mechanical block of conducting elements was mostly transient. Therefore our case would be unique in this regard. We have found only one similar case with shorter follow-up in the literature ${ }^{13}$ in which incessant LPFVT was unexpectedly abolished during catheter manipulation in the left ventricle.

In our case we stopped the procedure due to non-inducibility of the VT after the map completion. Even though catheter ablation was not performed, no VT recurrence has been documented during 60 months' follow-up.

We surmise that we caused mechanical trauma during the mapping of the posterior fascicle that damaged arrhythmogenic structures and subsequently led to long-term remission of the left posterior fascicular ventricular tachycardia.

\section{References}

1. Nogami A. Idiopathic left ventricular tachycardia: assessment and treatment. Card Electrophysiol Rev 2002; 6: 448-57.

2. Yamada T, Doppalapudi H, McElderry HT, Okada T, Murakami Y, Inden Y, et al. Idiopathic ventricular arrhythmias originating from the papillary muscles in the left ventricle: prevalence, electrocardiographic and electrophysiological characteristics, and results of the radiofrequency catheter ablation. J Cardiovasc Electrophysiol 2010; 21: 62-9.

3. Ouyang F, Cappato R, Ernst S, Goya M, Volkmer M, Hebe J, et al. Electroanatomic substrate of idiopathic left ventricular tachycardia: unidirectional block and macroreentry within the Purkinje network. Circulation 2002; 105: 462-9.

4. Nakagawa H, Beckman KJ, McClelland JH, Wang X, Arruda M, Santoro I, et al. Radiofrequency catheter ablation of idiopathic left ventricular tachycardia guided by a Purkinje potential. Circulation 1993; 88: 2607-17.

5. Tsuchiya T, Okumura K, Honda T, Honda T, Iwasa A, Yasue $\mathrm{H}$, et al. Significance of late diastolic potential preceding Purkinje potential in verapamil-sensitive idiopathic left ventricular tachycardia. Circulation 1999; 99: 2408-13.

6. Ma FS, Ma J, Tang K, Han H, Jia YH, Fang PH, et al. Left posterior fascicular block: a new endpoint of ablation for verapamil-sensitive idiopathic ventricular tachycardia. Chin Med J 2006; 119: 367-72. 
7. King A, Wen MS, Yeh SJ, Wang CC, Lin FC, Wu D. Catheter-induced atrioventricular nodal block during radiofrequency ablation. Am Heart J 1996; 132: 979-85.

8. Topilski I, Rogowski O, Glick A, Viskin S, Eldar M, Belhassen B. Catheter-induced mechanical trauma to fast and slow pathways during radiofrequency ablation of atrioventricular nodal reentry tachycardia: incidence, predictors, and clinical implications. Pacing Clin Electrophysiol 2007; 30: 1233-41.

9. Jacobson LB, Scheinman M. Catheter-induced intraHisian and intrafascicular block during recording of His bundle electrograms. Circulation 1974; 49: 579-84.

10. Wennevold A, Christiansen I, Lindenneg O. Complications in 4413 catheterizations of the right side of the heart. Am Heart J 1965; 69: 173-80.
11. Chiang CE, Chen SA, Wu TJ, Yang CJ, Cheng CC, Wang $\mathrm{SP}$, et al. Incidence, significance, and pharmacological responses of catheter-induced mechanical trauma in patients receiving radiofrequency ablation for supraventricular tachycardia. Circulation 1994; 90: 1847-54.

12. Belhassen B, Viskin S, Fish R, Glick A, Glikson M, Eldar M. Catheter-induced mechanical trauma to accessory pathways during radiofrequency ablation: incidence, predictors and clinical implications. J Am Coll Cardiol 1999; 33: 767-74.

13. Blomström-Lundqvist C, Blomström P, BeckmanSuurküla M. Incessant ventricular tachycardia with a right bundle-branch block pattern and left axis deviation abolished by catheter manipulation. Pacing Clin Electrophysiol 1990; 13: 11-6. 